\title{
Direct thrombin inhibitors
}

\section{Catherine J. Lee ${ }^{1} \&$ Jack E. Ansell ${ }^{2}$}

${ }^{1}$ Department of Medicine, Memorial Sloan-Kettering Cancer Center, New York, USA and ${ }^{2}$ Department of Medicine, North Shore-LIJ-Lenox Hill Hospital, New York, USA
Correspondence

Dr Catherine J. Lee MD, Department of Medicine, Memorial Sloan-Kettering

Cancer Center, 1275 York Avenue, New York, NY 10065, USA.

Tel.: +1 6468883065

Fax: +16464220937

E-mail: leec@mskcc.org

Keywords

argatroban, bivalirudin, dabigatran etexilate, hirudin, thrombin, venous thromboembolism

Received

17 November 2010

Accepted

10 January 2011

Accepted Article

17 January 2011

Heparins and vitamin $\mathrm{K}$ antagonists have been the primary agents used for anticoagulation in certain cardiovascular and thromboembolic diseases for over 50 years. However, they can be difficult to administer and are fraught with limitations. In response to the need for new anticoagulants, direct thrombin inhibitors (DTIs) have been developed and investigated for their utility in prophylaxis and treatment of venous thromboembolism (VTE), heparin-induced thrombocytopenia (HIT), acute coronary syndromes (ACS), secondary prevention of coronary events after ACS, and nonvalvular atrial fibrillation. Currently, four parenteral direct inhibitors of thrombin activity are FDA-approved in North America: lepirudin, desirudin, bivalirudin and argatroban. Of the new oral DTIs, dabigatran etexilate is the most studied and promising of these agents. This review discusses the clinical indications and efficacy of these direct thrombin inhibitors as well as future directions in anticoagulant therapy.

\section{Introduction}

Thrombin plays a central role in the generation of a thrombus. Once formed, thrombin activates factors V, VIII and XI, which are involved in generating more thrombin, and it also activates factor XIII, a protein involved in fibrin crosslinking and clot stabilization. Thrombin's principal function is to convert soluble fibrinogen to insoluble fibrin, while also stimulating platelet activation. Thrombin can be inhibited directly or indirectly by the binding of thrombininhibiting drugs to one or two of its three domains: the active site and exosites 1 and 2. Exosite 1 is the fibrinbinding site of thrombin and exosite 2 serves as the heparin-binding domain [1]. Traditional anticoagulants such as unfractionated heparin (UFH) and low-molecularweight heparin $(\mathrm{LMWH})$ inhibit free thrombin in an indirect manner by binding simultaneously to antithrombin and exosite 2, thereby forming a heparin-thrombinantithrombin complex (Figure 1). However, heparins also can simultaneously bind to both fibrin and thrombin and act as a bridge between them, thereby enhancing thrombin's affinity for fibrin and increasing the concentration of thrombin-bound fibrin. This fibrin-heparin-thrombin complex occupies both thrombin exosites but leaves the active site ezymatically protected from inactivation as the heparin-antithrombin complex cannot bind to fibrin- bound thrombin, resulting in further thrombus growth $[2$, 3]. In addition to its inability to neutralize fibrin-bound thrombin, other limitations of heparin include its binding to various plasma proteins, creating an unpredictable dose-dependent anticoagulant response, need for routine dose-adjustments and anticoagulant monitoring and heparin-induced thrombocytopenia (HIT) [4].

Direct thrombin inhibitors (DTIs) bind directly to thrombin and do not require a cofactor such as antithrombin to exert their effect. DTIs can inhibit both soluble thrombin and fibrin-bound thrombin [4]. Other key advantages include a more predictable anticoagulant effect compared with heparins because of their lack of binding to other plasma proteins [5], an anti-platelet effect [6] and the absence of immune-mediated thrombocytopenia [7].

Both parenteral and oral direct thrombin inhibitors have been investigated for prophylaxis and treatment of venous thromboembolism (VTE), prevention of thromboembolic complications in patients with HIT or at risk for HIT and undergoing percutaneous coronary intervention $(\mathrm{PCl})$, acute coronary syndromes (ACS) with and without percutaneous transluminal coronary angioplasty (PTCA), secondary prevention of coronary events after ACS and nonvalvular atrial fibrillation [8,9]. Currently, four parenteral DTIs are approved for use as anticoagulants in the United States: lepirudin, desirudin, bivalirudin and 


\section{Thrombin}

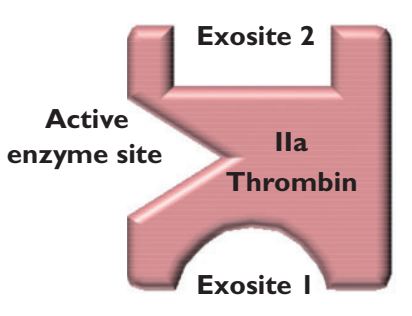

Exosite I

Fibrin binding site

Exosite 2

Heparin binding site

\section{Unfractionated heparin}

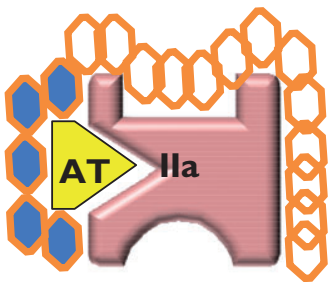

Lepirudin/

Desirudin

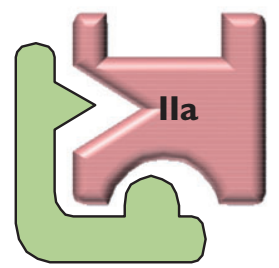

Bivalirudin

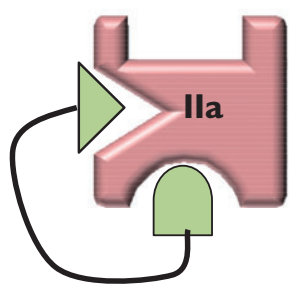

Low molecular

weight heparin

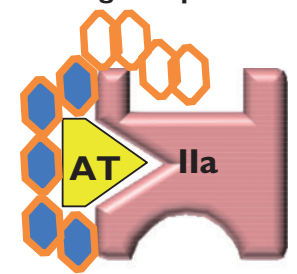

Argatroban

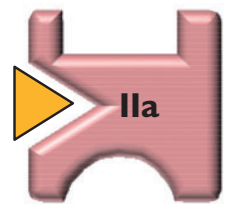

Dabigatran



\section{Figure 1}

Schematics of the interaction of thrombin with six different anticoagulants. Unfractionated heparin (UFH) - UFH mediates its affect through binding to antithrombin and enhancing its reactivity with the enzymatic site of thrombin. UFH requires an additional 13 saccharides that bind to the heparin binding site to maximize its interaction with thrombin. UFH is thus an indirect, parenteral inhibitor of thrombin. Low molecular weight heparin (LMWH) - LMWH lacks the longer chains of UFH and has less binding to thrombin thus decreasing its ability to neutralize thrombin. LMWH is thus an indirect, parenteral inhibitor of thrombin. Lepirudin/Desirudin - Lepirudin and desirudin bind directly and strongly to both the active enzymatic site and exosite 1 of thrombin to inhibit its activity. Lepirudin and desirudin are direct, parenteral inhibitors of thrombin. Argatroban - Argatroban is a small molecule that binds reversibly to the active enzymatic site of thrombin. Argatroban is a direct, parenteral inhibitor of thrombin. Bivalirudin - Bivalirudin is a modified form of hirudin with four glycine residues connecting two amino acids sequences important for binding to thrombin. It is a more reversible inhibitor of thrombin than is lepirudin, and is a direct, parenteral inhibitor of thrombin. Dabigatran - Dabigatran is a small molecule that binds reversibly to the active enzymatic site of thrombin. Dabigatran is an oral, direct inhibitor of thrombin

agratroban. Their unique pharmacologic and clinical properties are summarized in Table 1. Several oral compounds are currently under investigation, with dabigatran etexilate furthest along in development.

\section{Parenteral direct thrombin inhibitors}

\section{Recombinant hirudins: lepirudin and desirudin} Lepirudin and desirudin are derivatives of hirudin, a peptide originally isolated from the salivary glands of medicinal leeches [10] that were developed by recombinant technology in Saccharomyces cerevisiae [7]. Both recombinant hirudins (r-hirudins) are bivalent direct thrombin inhibitors that bind simultaneously to the active site and exosite 1 domain on thrombin, an interaction that increases their specificity for thrombin [7]. They also have the highest affinity for thrombin as they rapidly form essentially irreversible, 1:1 stoichiometric complexes [11]. Compared with hirudin their affinity is 10 times weaker for thrombin, however, they are still considered the most potent of all the thrombin inhibitors [7, 10]. The plasma half-life of the r-hirudins after intravenous (i.v.) injection and subcutaneous (s.c.) administration is 60 and $120 \mathrm{~min}$, respectively [12].

Lepirudin is licensed for the treatment of thrombosis complicating HIT. It is given as an intravenous infusion with 


\section{Table 1}

Pharmacologic and clinical properties of the parenteral direct thrombin inhibitors

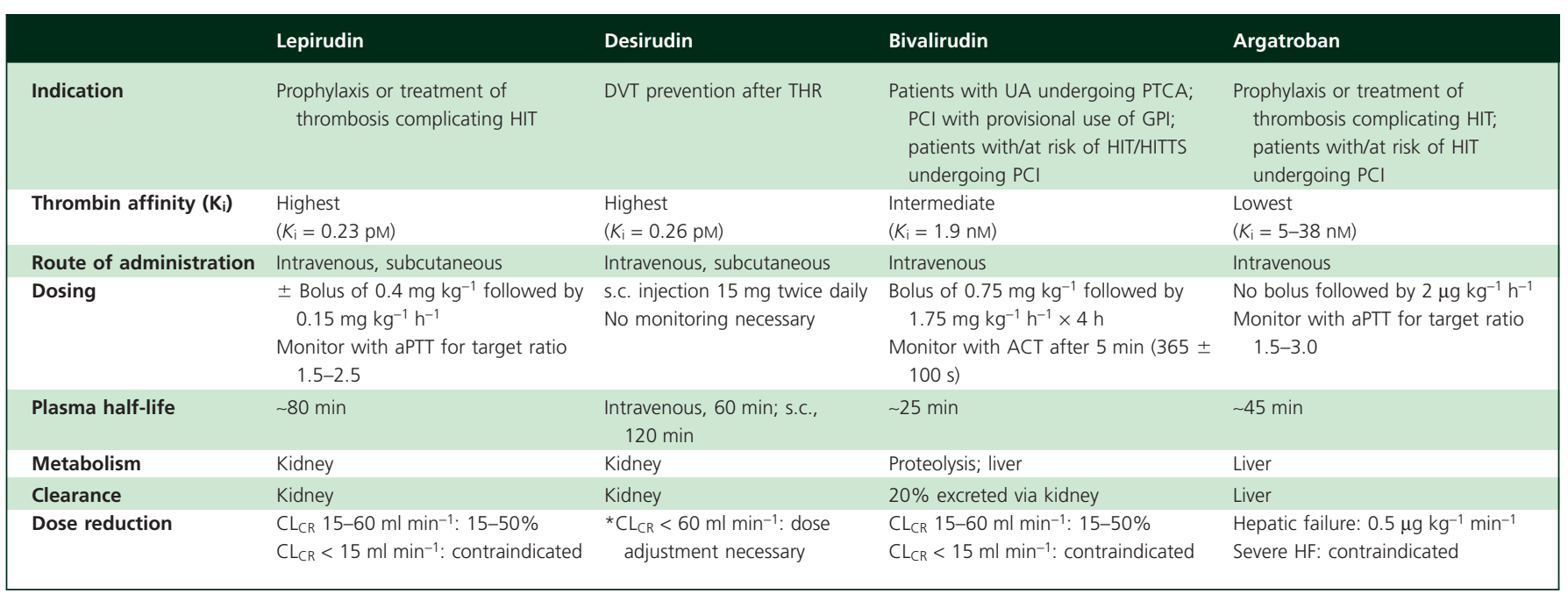

ACT, activated clotting time; aPTT, activated partial thromboplastin time; $\mathrm{CLCR}_{\mathrm{r}}$ creatinine clearance; DVT, deep venous thrombosis; GPI, glycoprotein inhibitor; HF, hepatic failure; HIT, heparin-induced thrombocytopenia; HITTS, heparin-induced thrombocytopenia with thrombosis syndrome; PCI, percutaneous coronary intervention; PCTA, percutaneous transluminal angioplasty; s.c., subcutaneous; THR, total hip replacement; UA, unstable angina. * Recent data suggest that desirudin may be used without dose adjustments in patients with moderate impairment.

or without a bolus, and its dosing is dependent on body weight. As lepirudin is renally excreted, dose adjustments are required in patients with renal impairment [13]. Significant limitations to the use of lepirudin are its narrow therapeutic window and potential for increased bleeding events [7]. Furthermore, formation of antihirudin antibodies following treatment of HIT in $40 \%$ of patients treated with lepirudin has been reported. These immunogenic complexes may delay the renal excretion of lepirudin and cause drug accumulation [14, 15]. Therefore, dose adjustment based on aPTT is required during treatment. Although rare, anaphylaxis can also occur if patients with hirudin-induced antibodies are re-exposed to hirudin [15]. Currently, there is no specific antidote to reverse the effects of the recombinant hirudins or any of the other direct thrombin inhibtitors [16].

Desirudin is the only fixed-dose subcutaneously administered DTI approved by the Federal Drug Administration (FDA) for postoperative prevention of VTE in patients undergoing elective hip replacement surgery [17]. In March 2010 it became available in the United States. Two randomized, double-blind, multi-centre clinical studies compared the efficacy and safety of desirudin (15 mg s.c. twice daily injections) with unfractionated heparin (UFH) (5000 units s.c. three times daily) and enoxaparin ( $40 \mathrm{mg}$ s.c. daily) for the prophylaxis of DVT in patients undergoing major orthopaedic surgeries. Desirudin was superior to both heparin anticoagulants $(P<0.001$ for both) after 8-12 days of treatment, while showing a similar safety profile $[18,19]$. Desirudin is also currently under investigation as a potential anticoagulant for patients with HIT with or without thrombosis. The PREVENT-HIT study is a small, randomized, open-label trial comparing the clinical efficacy, safety and economic utility of fixed-dose s.c. desirudin against argatroban [20]. The study is now completed and results will be soon published. Desirudin, like lepirudin has been investigated for its anticoagulant efficacy and prevention of adverse outcomes in patients with acute coronary syndromes with or without percutaneous coronary interventions. Results from both the HELVETICA and GUSTO-Illb trials demonstrated a significant reduction in the incidence of death or MI with desirudin compared with unfractionated heparin, particularly in the most unstable patients [21,22]. However, desirudin was associated with an increased incidence of major bleeding events.

After s.c. administration, desirudin reaches maximum plasma concentrations after $1-3 \mathrm{~h}$, has a terminal half-life of $2 \mathrm{~h}$ and is predominantly $(80-90 \%)$ renally excreted. Advantages of s.c. desirudin include the lack of weightbased dose calculations and need for routine monitoring. In the setting of severe renal insufficiency $\left(\mathrm{CL}_{\mathrm{CR}} \leq\right.$ $30 \mathrm{ml} \mathrm{min}^{-1}$ ), dose reduction and monitoring with aPTT are strongly recommended $[7,14]$. Results from a recent pharmacokinetics study suggest that dosage adjustments and aPTT monitoring are unnecessary in patients with moderate renal impairment $\left(\mathrm{CL}_{\mathrm{CR}_{R}} 31-60 \mathrm{ml} \mathrm{min}{ }^{-1}\right)$ [23].

\section{Bivalirudin}

Bivalirudin is an engineered 20-amino acid, synthetic, bivalent analogue of hirudin with a thrombin inhibition activity nearly 800 times weaker than that of hirudin [24]. Unlike 
the recombinant hirudins, the binding of bivalirudin to thrombin is reversible because once bound, it is slowly cleaved by thrombin. As a result, thrombin activity is only transiently inhibited and the enzymatic activity of the thrombin site is restored. This reversible relationship between bivalirudin and thrombin may contribute to its decreased bleeding risk and improved safety profile when compared with r-hirudins $[4,25]$. Bivalirudin is given intravenously, has an immediate onset of action with therapeutic activated clotting times (ACT) achieved within $5 \mathrm{~min}$ after initiating therapy, and a half-life of $25 \mathrm{~min}$, all characteristics that are favourable for a PCl setting [7, 14]. Bivalirudin is mainly cleared by proteolytic cleavage and hepatic metabolism [26]. However, $20 \%$ of the dose is renally eliminated and dose adjustments are necessary in patients with moderate renal insufficiency $[27,28]$. Bivalirudin is contraindicated in patients with severe renal impairment [7].

Bivalirudin has been extensively investigated in various clinical trials for its efficacy in reducing death, myocardial infarction (MI) or repeat vascularization in patients with ACS undergoing $\mathrm{PCl}$. Reviews of these studies are available elsewhere [14, 29, 30]. The Bivalirudin Angioplasty Study showed that bivalirudin had a better efficacy in preventing these primary outcomes as well as a lower bleeding rate when compared with UFH in over 4000 patients undergoing PTCA for unstable or post-infarct angina [31]. This led to the 2000 FDA-approval of bivalirudin as an alternative anticoagulant to heparin in patients undergoing PTCAs. In 2005, the FDA expanded its approval of bivalirudin to include provisional use of concomitant glycoprotein llb/ Illa inhibitors (GPI) for patients undergoing elective or urgent $\mathrm{PCl}$ procedures [32]. This decision was based on data from the Randomized Evaluation of PCI Linking Angiomax to Reduced Clinical Events (REPLACE-2) study, which demonstrated a non-inferiority of bivalirudin to UFH (each with provisional GPI) in regards to the combined primary endpoint (mortality, MI, urgent revascularization or severe bleeding), and with significantly less bleeding [33].

Additional studies have evaluated the use of bivalirudin in patients with ST-elevation MI (STEMI) [34], and in HIT patients undergoing $\mathrm{PCl}$ or cardiopulmonary bypass surgery [35-37]. Results from the ATBAT trial showed bivalirudin to have a safe and effective anticoagulant effect during $\mathrm{PCl}$ procedures in patients with HIT/HITTS [35]. Soon after, the FDA expanded its approval of bivalirudin to include its use as an alternative to heparin in HIT patients with or without thrombosis undergoing $\mathrm{PCl}$.

\section{Argatroban}

Argatroban is a small (527 Da), univalent DTI that noncovalently and reversibly binds to the active site on thrombin [7]. Argatroban is licensed in the United States for the prophylaxis or treatment of thrombosis in patients with HIT and for anticoagulation in patients with a history of HIT or at risk of HIT undergoing $\mathrm{PCl}$. It is given as an intravenous infusion with a starting dose of $2 \mu \mathrm{g} \mathrm{kg}^{-1} \mathrm{~min}^{-1}$ and does not require a bolus injection [13]. Steady-state plasma concentrations are reached in $10 \mathrm{~h}$, and the plasma half-life of argatroban is approximately $45 \mathrm{~min}$. As argatroban is hepatically metabolized and predominantly excreted through the biliary system, dose adjustments are necessary in patients with hepatic but not renal impairment. The aPTT and ACT can be used to monitor its effect; dosing is titrated to maintain an aPTT of 1.5-3 times that of baseline. Argatroban prolongs thrombin-dependent coagulation tests and thus prolongs the prothrombin time (PT) and INR. When used together with warfarin, the INR is prolonged greater than that of warfarin alone. Separate dosing and monitoring guidelines should be followed. Argatroban therapy can be discontinued when the INR during concomitant use of warfarin and argatroban is greater than $4[7,14]$.

\section{Oral direct thrombin inhibitors}

Oral lla inhibitors represent a new era of anticoagulation for the prevention and treatment of venous and selected arterial thromboembolisms. Ximelagatran is the oral double prodrug of melagatran and was the first oral direct thrombin inhibitor developed. Studies demonstrated it to be as effective as the traditional anticoagulants in the prevention and treatment of venous and arterial thromboses and secondary prevention of cardiovascular events post MI. The approval of ximelagatran in Europe for prevention of venous thromboembolism in major elective orthopaedic surgeries marked a milestone in the advancement of oral anticoagulants as it had been almost 60 years prior since the introduction of oral vitamin $\mathrm{K}$ antagonists. However, ximelagatran was removed from the European market approximately 20 months later and was never approved in North America after studies showed that therapy greater than 35 days was associated with a risk of hepatotoxicity [38].

Like ximelagatran, dabigatran etexilate is an orally active double prodrug that is rapidly converted to dabigatran, a low-molecular weight molecule that acts as a specific, potent and reversible direct thrombin inhibitor. It is currently the most studied and promising of the oral direct thrombin inhibitors. Key clinical advantages of this drug include a rapid onset of action, lack of interaction with cytochrome P450 enzymes or with other food and drugs, excellent safety profile, lack of need for routine monitoring, broad therapeutic window and a fixed-dose administration.

The efficacy and safety of dabigatran etexilate against current standard anticoagulant therapy have been evaluated for multiple indications such as primary VTE prevention after hip and knee surgeries, treatment of acute deep vein thrombosis (DVT) and/or pulmonary embolism (PE) and their secondary prevention, prevention of stroke and 
systemic embolism in patients with non-valvular atrial fibrillation (AF) and secondary prevention of cardiac events in patients with ACS (Table 2). Unlike ximelagatran, long-term use of dabigatran has not been associated with liver toxicity. Dabigatran etexilate was approved in Canada and Europe in 2008 for the prevention of venous thromboembolism after elective total hip replacement and/or total knee replacement. In October 2010, the US FDA advisory committee approved dabigatran etexilate for stroke prevention in patients with AF.

\section{Metabolism, pharmacokinetics and pharmacodynamics of oral DTIs}

\section{Dabigatran etexilate and dabigatran}

Dabigatran is a small (472 Da) peptidomimetic that directly inhibits thrombin by binding to its active site via ionic interactions. Dabigatran was synthesized as a derivative of the peptide-like, benzamidine-based thrombin inhibitor AA-[alpha]-naphthylsulphonylglycyl-4amidinophenylalanine piperidine ([alpha]-NAPAP). It rapidly and reversibly inhibits both clot-bound and free thrombin in a concentration dependent manner with an inhibition constant $\left(K_{\mathrm{i}}\right)$ of $4.5 \mathrm{nmol} \mathrm{I}^{-1}$. It also exhibits high specificity for thrombin over other serine proteases. As a highly polar and charged molecule, dabigatran has poor intestinal absorption and no bioavailability after oral absorption. The conversion of the carboxylate group of dabigatran into an ester group and the masking of the amidinium moiety as a carbamate ester led to the development of dabigatran etexilate, a highly lipophilic and gastrointestinally absorbed double prodrug. After oral administration, dabigatran etexilate is rapidly converted to active dabigatran, via two intermediates (BIBR 951 and BIBR 1087) after cleavage of both lipophilic groups by serine esterases (39) (Figure 2).

The absolute bioavailability of dabigatran after oral absorption is low (6-7\%) and is independent of the dose of the prodrug [39]. As dose-escalation studies have shown that dabigatran plasma concentrations increase in a doseproportional manner [40], relatively high doses of dabigatran etexilate are necessary to achieve adequate plasma concentrations. Dabigatran etexilate is also optimally and more consistently absorbed in an acidic environment. To achieve this goal, a new capsule formulation containing multiple small pellets containing a tartaric acid core and coated with dabigatran etexilate was developed. The advantage of this modification is that dabigatran etexilate brings its optimal $\mathrm{pH}$ environment to the site of absorption (i.e. gastrointestinal tract). Therefore, variations in intrinsic gastric $\mathrm{pH}$ do not significantly affect the extent of its absorption, even in the presence of proton pump inhibitors [41]. Another significant characteristic of this prodrug is the lack of involvement by the P450 (CYP) isoenzymes or other oxidoreductases in the metabolism of dabigatran etexilate to dabigatran. Rather, ubiquitous esterases present in plasma are involved in the conversion. As in vitro studies also show that dabigatran does not inhibit the cytochrome P450 enzymes, the potential for drug-drug interactions is low [39].

After absorption of dabigatran etexilate, bioconversion to dabigatran occurs in enterocytes, hepatocytes and the portal vein. Twenty percent of dabigatran is conjugated to glucuronic acid to yield pharmacologically activated glucuronide conjugates [41]. Once metabolized to dabigatran, the prodrug and its intermediate metabolites, BIBR 951 and BIBR 1087, are trace detectable $\left(\sim 0.5 \mathrm{ng} \mathrm{ml}^{-1}\right)$ in the plasma of healthy subjects for approximately $2 \mathrm{~h}$ after ingestion [42]. Of note, the absorption and metabolism of dabigatran etexilate has also been tested in patients with moderate hepatic impairment. Although the bioconversion rate of dabigatran etexilate to its active form was slightly slower than that in matched healthy control subjects, the mean values for the area under the plasma concentration-time curves (AUCs), terminal half-life and renal clearance were comparable between the two groups. In addition, results from several clot-based assays were also similar between the healthy controls and patients with hepatic insufficiency [43]. These findings demonstrate that moderate hepatic impairment does not affect the efficacy or safety profile of dabigatran, and that these patients can be given unadjusted doses of dabigatran etexilate.

Renal excretion is the primary elimination pathway for dabigatran in humans. The remainder undergoes conjugation with glucuronic acid to form acylglucuronides, which are excreted via the bile. Both the bioavailability and extent of exposure to dabigatran are elevated in renal

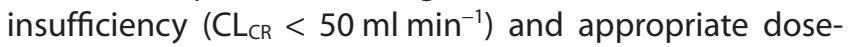
reduction of dabigatran etexilate is required. Although dabigatran is dialyzable, it is contraindicated in patients with severe renal impairment $\left(\mathrm{CL}_{\mathrm{CR}}<30 \mathrm{ml} \mathrm{min}^{-1}\right)$ [42].

The key pharmacokinetics and pharmacodynamics properties of dabigatran etexilate are summarized in Table 3. After oral administration of the prodrug, dabigatran etexilate is rapidly converted to dabigatran, with peak plasma concentrations $\left(C_{\max }\right)$ achieved within $1.5-2 \mathrm{~h}$ in healthy volunteers regardless of age or gender $[39,42,44]$. After absorption, a rapid distribution phase occurs followed by a prolonged elimination time. The volume of distribution of dabigatran is $60-70 \mathrm{l}$, indicating moderate volume distribution [42]. The mean plasma terminal halflife of dabigatran in healthy young and elderly volunteers is $12-14 \mathrm{~h}$, independent of dose, and accordingly steadystate concentrations are attained within 3 days with multiple dosing and without evidence of significant accumulation [40,45]. The overall exposure is increased by $40-60 \%$ in healthy elderly volunteers compared with younger subjects primarily secondary to reduced renal clearance and slower elimination of dabigatran [45]. Food can prolong the time to peak plasma dabigatran concentrations by $2 \mathrm{~h}$ without having an effect on its extent of 


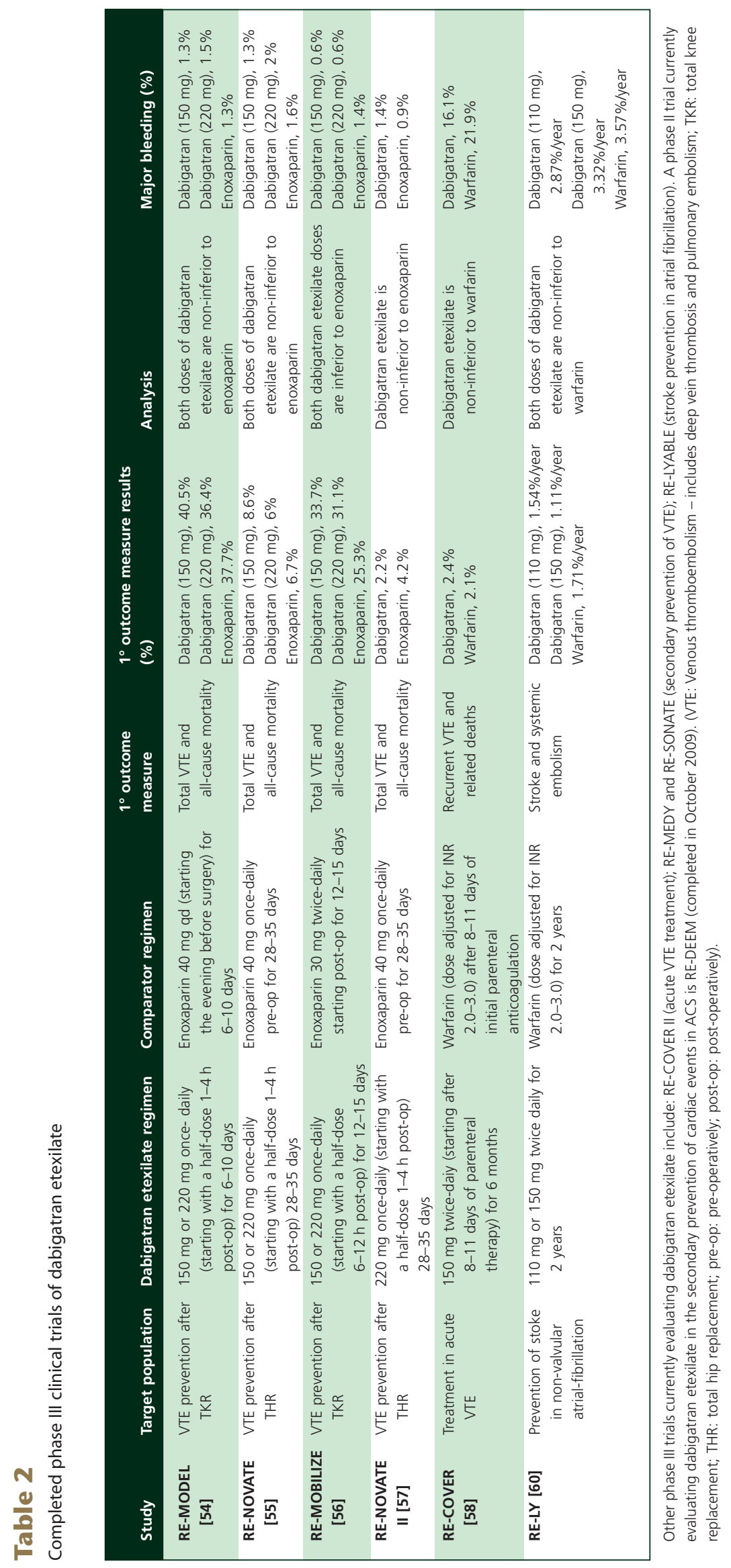




\section{Dabigatran etexilate}
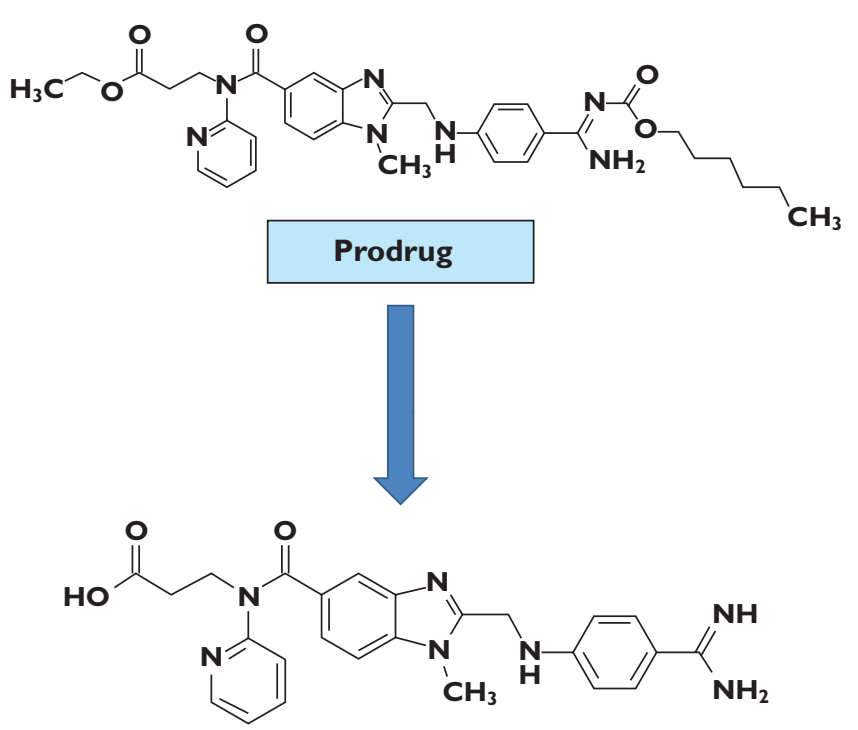

Dabigatran

\section{Figure 2}

Chemical structures of the double prodrug, dabigatran etexilate and its active form, dabigatran

absorption (AUC) [44]. However the pharmacokinetic profile of dabigatran is not affected by the use of co-medications, such as opioids [44], diclofenac [46], atorvastatin [47] or digoxin $[9,41]$. A reduced dose of dabigatran etexilate is recommended when co-administered with amiodarone or other strong P-glycoprotein (P-gp) inhibitors like verapamil, clarithromycin and others. Dabigatran is contraindicated with quinidine use. Other potent P-gp inducers such as rifampicin or St John's wort may reduce the systemic exposure of dabigatran $[48,49]$.

Prolongation of blood coagulation parameters (aPTT, PT, TT, ECT) occurs in parallel with increasing concentrations of dabigatran, and peak clotting times coincide with the $C_{\max }$ of dabigatran ( $2 \mathrm{~h}$ after oral administration). Similarly, $12 \mathrm{~h}$ after oral administration of dabigatran (time of first half-life), the prolongation of blood coagulation returned to $50 \%$ of the maximum effect $[40,42]$. The thrombin time (TT) is most responsive to dabigatran in the clinically relevant plasma concentration range whereas the aPTT and prothrombin time (PT) are least so. The ECT assay may be the most useful test for measuring thrombin inhibition as it has been reported as having adequate sensitivity and precision with predictable and reproducible results $[41,50]$. Currently under development is a diluted thrombin time assay (Hemoclot ${ }^{\circledR}$ Thrombin Inhibitor Assay),

\section{Table 3}

Main characteristics of dabigatran etexilate

\begin{tabular}{|c|c|}
\hline \multicolumn{2}{|l|}{ Pharmacology } \\
\hline Route of administration & Oral \\
\hline Inhibitor type & Selective, reversible DTI $\left(\mathrm{K}_{\mathrm{i}}=4.5 \mathrm{nM} \mathrm{L}^{-1}\right)$ \\
\hline Molecular Weight & $628 \mathrm{Da}$ (prodrug); $472 \mathrm{Da}$ (active) \\
\hline Prodrug & $\begin{array}{l}\text { Double prodrug converted to active form via } \\
\text { two intermediates }\end{array}$ \\
\hline \multicolumn{2}{|l|}{ Absorption \& Metabolism } \\
\hline Oral bioavailability & $6-7 \%$ (decreased by PPI by $20-25 \%$ ) \\
\hline Involvement of CYP450 & No \\
\hline Food Effect & Delayed absorption \\
\hline Plasma protein binding & $35 \%$ \\
\hline Metabolism & $\begin{array}{l}\text { Occurs in hepatocytes and enterocytes; } 20 \% \\
\text { metabolized to yield activated glucuronide } \\
\text { conjugates }\end{array}$ \\
\hline Elimination & Biliary $20 \%$; Renally $80 \%$ \\
\hline \multicolumn{2}{|l|}{ Pharmacokinetics } \\
\hline Pharmacokinetic profile & Linear \\
\hline$T_{\max }(h r)$ & $1-3$ \\
\hline Half-life (hr) & $12-14$ \\
\hline \multicolumn{2}{|l|}{ Clinical considerations } \\
\hline Approved indications & $\begin{array}{l}\text { VTE prophylaxis after hip- or knee- } \\
\text { replacement surgery (EU and Canada) }\end{array}$ \\
\hline Dosage & 150 or $220 \mathrm{mg}$ once daily (VTE prophylaxis) \\
\hline Dose reduction & $\begin{array}{l}\text { Moderate renal impairment }(\mathrm{CrCl}< \\
\left.50 \mathrm{ml} \mathrm{min}^{-1}\right) \text {; contraindicated when } \mathrm{CrCl}< \\
\left.30 \mathrm{ml} \mathrm{min}^{-1}\right)\end{array}$ \\
\hline Monitoring & Not needed \\
\hline Potential drug interactions & $\begin{array}{l}\text { Quinidine, verapamil, amiodarone, rifampicin, } \\
\text { St. John's wort, strong P-glycoprotein } \\
\text { inhibitors }\end{array}$ \\
\hline
\end{tabular}

DTI, direct thrombin inhibitor; $\mathrm{CrCl}$, creatinine clearance; EU, European Union; PPI, proton pump inhibitor; VTE, venous thromboembolism.

which uses dabigatran standards for quantitative measurement of DTI activity in plasma. A direct relationship between dabigatran concentration and clotting time (from 30-75 s) has been reported [50].

\section{Clinical efficacy of dabigatran etexilate}

\section{Prevention of venous thromboembolism after hip or knee replacement surgery}

The efficacy and safety of dabigatran for prevention of VTE in elective major orthopaedic surgeries was first demonstrated in the Boehringer Ingelheim Study in ThROmbosis (BISTRO) phase II trials [44, 51, 52]. The principle results from this set of studies showed that increasing doses of dabigatran etexilate decreased total VTE in a dosedependent manner, and the incidence of major VTE (proximal DVT and/or PE) was lower in groups with any dose of dabigatran etexilate $(1.7 \%-5.0 \%)$ compared with enoxaparin (5.6\%). Although the incidence of major bleeding events was significantly lower with $50 \mathrm{mg}$ twice daily of dabigatran etexilate when compared with enoxaparin $(0.3$ 
vs. $2.0 \%, P=0.047)$, this increased at the higher, more effective doses (3.8-4.7\%). The efficacy and safety profile between once daily and twice daily dosing of dabigatran etexilate (same total daily dose) was comparable. Further pharmacokinetic and pharmacodynamic studies on patients enrolled in BISTRO II supported an optimal efficacy-safety dosing regimen for phase III trials, consisting of once daily doses of $150 \mathrm{mg}$ or $220 \mathrm{mg}$, with half doses of $75 \mathrm{mg}$ and $110 \mathrm{mg}$ given on the day of surgery [52].

Pooled analysis of the results from the completed RE-MOBLIZE, RE-MODEL and RE-NOVATE phase III trials, which involved a combined total of 8210 patients, concluded that dabigatran etexilate is as efficacious and safe as enoxaparin in the prevention of VTE after hip or knee arthroplasty [53]. Two different doses of dabigatran etexilate, $150 \mathrm{mg}$ or $220 \mathrm{mg}$ once daily with half doses, $75 \mathrm{mg}$ or $110 \mathrm{mg}$, on the first day were examined and compared against the approved enoxparin regimen for the respective region in all three trials. RE-MODEL and RE-NOVATE, both performed in the European Union and other nonNorth American countries, found both doses of dabigatran non-inferior to enoxaparin ( $40 \mathrm{mg}, 12 \mathrm{~h}$ presurgery). Rates of total VTE and all-cause mortality were $36.4 \%(P<0.0003)$ and $40.5 \%(P<0.017)$ for doses of $220 \mathrm{mg}$ and $150 \mathrm{mg}$, respectively, vs. $37.7 \%$ for enoxaparin in RE-MODEL [54]. Similar findings were observed in RE-NOVATE $[6.0 \%(P<$ $0.0001), 8.6 \%(P<0.0001)$, and $6.7 \%$ in dabigatran $220 \mathrm{mg}$, $110 \mathrm{mg}$, and enoxaparin $40 \mathrm{mg}$ daily, respectively,] [55]. In both studies, rates of major bleeding events were similar across all treatment groups. Data from these two trials led to the approval of use of dabigatran etexilate for the primary prevention of VTE after total knee or hip replacement in the EU. However, results from RE-MOBILIZE failed to show non-inferiority of dabigatran (started 6-12 $\mathrm{h}$ after surgery) to enoxaparin (30 mg twice daily started $12-24 \mathrm{~h}$ post surgery). Total VTE and all-cause mortality rates were significantly higher in the dabigatran $220 \mathrm{mg}(31.1 \%, P=$ $0.02)$ and $150 \mathrm{mg}(33.7 \%, P<0.001)$ groups compared with enoxaparin (25.3\%) [56]. Rates of major bleeding were not significantly different between both dabigatran groups and enoxaparin group. The failure to achieve noninferiority is likely secondary to the delay in the administration of dabigatran etexilate after surgery as well as the higher dosing of enoxaparin [56]. In response to these results, a fourth phase III trial, RE-NOVATE II, was initiated and recently completed. This double-blind, non-inferiority trial examined 2055 patients in North America with a goal to evaluate the efficacy of dabigatran $220 \mathrm{mg}$ once daily vs. enoxaparin $40 \mathrm{mg}$ once daily over a course of 28-35 days for VTE prevention post-hip replacement surgery. Dabigatran was found to be at least as effective as enoxaparin in preventing total VTE and all-cause mortality $(7.7 \%$ vs. $8.8 \%$, $P<0.0001)$ and also associated with significantly lower rates of VTE-related death $(2.2 \%$ vs. $4.2 \%, P<0.03)$. The rates of major bleeding were not significantly different from each other [57]. These results, in addition to the results from RE-NOVATE confirm that once daily dosing of dabigatran is as efficacious and safe as enoxaparin in preventing VTE after total hip replacement surgery.

\section{Treatment and secondary prevention of venous thromboembolism}

The RE-COVER trial demonstrated that $150 \mathrm{mg}$ twice daily dabigatran etexilate had a similar efficacy and safety profile as warfarin (adjusted for INR 2-3) in the treatment of acute symptomatic venous thromboembolism. Patients ( $n=2539$ ) with acute, symptomatic, objectively verified proximal deep-vein thrombosis of the legs or pulmonary embolism were randomized to receive 6 months of either oral dabigatran etexilate $150 \mathrm{mg}$ twice daily or warfarin (adjusted for INR 2-3) after initial parenteral anticoagulation therapy (median $=9$ days). The primary endpoint of either recurrent venous thromboembolism or fatal pulmonary embolism during the treatment period occurred in $2.4 \%$ of patients treated with dabigatran compared with $2.1 \%$ of patients receiving warfarin. Rates of major bleeding with dabigatran were similar to warfarin ( $1.6 \%$ vs. $1.9 \%$, respectively). However a significant decrease in any bleeding events was observed for dabigatran when compared with warfarin $(16.1 \%$ vs. $21.9 \%$, hazard ratio of $0.71,95 \% \mathrm{Cl}$ $0.59,0.85, P<0.001$ ) [58]. A second trial comparing dabigatran etexilate with warfarin in the treatment of acute VTE is underway (RE-COVER II). As well, two trials (RE-MEDY and RE-SONATE) are currently ongoing to evaluate dabigatran etexilate against warfarin in the secondary prevention of venous thromboembolism.

\section{Prevention of stroke in non-valvular atrial fibrillation}

Results from the double-blind, dose-escalating phase II trials PETRO and PETRO-Ex showed that a dose of $150 \mathrm{mg}$ twice daily was as effective and safe as warfarin in the prevention of thromboembolic events in patients with non-valvular atrial fibrillation [59]. More recently, results from the phase III trial RE-LY demonstrated that the rate (percent per year) of the primary outcome (stroke or systemic embolism) was significantly lower with dabigatran etexilate $150 \mathrm{mg}$ twice daily (1.11\%) and non-inferior with $110 \mathrm{mg}$ twice daily (1.54\%) compared with warfarin $(1.71 \%)$ in patients with $\mathrm{AF}$ and at least one additional risk factor for stroke $\left(\mathrm{CHADS}_{2}\right.$ score $\left.\geq 1\right)$. The rates of haemorrhagic stroke were significantly lower with $150 \mathrm{mg}(0.10 \%$, $P<0.001)$ and $110 \mathrm{mg}(0.12 \%, P<0.001)$ twice daily doses of dabigatran etexilate vs. warfarin $(0.38 \%)$. The rate of major bleeding was significantly higher in the group receiving warfarin $(3.57 \%)$ compared with those receiving the lower dose of dabigatran $(2.87 \%$ for $110 \mathrm{mg}$ twice daily) and was non-inferior to those receiving the higher dose (3.32\% for $150 \mathrm{mg}$ twice daily). The study concluded that when compared with adjusted-dose warfarin, $110 \mathrm{mg}$ twice daily dabigatran was associated with a similar rate of 
stroke but less risk of major bleeding, while a dose of $150 \mathrm{mg}$ twice daily prevented more strokes but had a similar rate of major haemorrhage [60]. A long-term study, RELY-ABLE, is currently underway to evaluate the safety profile of dabigatran in these patients. These findings also suggest the potential ability to choose appropriately the dose of dabigatran depending on the patient's risk profile for stroke and bleeding.

\section{Prospective indications for dabigatran etexilate}

\section{Secondary prevention of coronary events after acute coronary syndrome}

The placebo-controlled, dose-finding phase II trial, RandomizEd Dabigatran Etexilate Dose Finding Study in Patients With Acute Coronary Syndromes Post Index Event With Additional Risk Factors for Cardiovascular Complications Also Receiving Aspirin and Clopidogrel (RE-DEEM), was completed in October 2009. Over 1800 patients with an acute ST-segment elevation or non ST-segment elevation $\mathrm{Ml}$ and at least one risk factor for a new ischaemic cardiovascular event were randomized to receive either placebo or one of four doses of dabigatran etexilate ranging from 50 to $150 \mathrm{mg}$ twice daily in conjunction with standard dual antiplatelet therapy. The primary aim of the study was to evaluate the safety of dabigatran as measured by the composite of major and clinically relevant minor bleeding events during 6 months of treatment. Although a dose-dependent increase in bleeding complications was observed, the 6 month rates of major bleeding did not exceed $2 \%(P<0.001)$. Deemed as safe to use in patients after an acute coronary syndrome, the investigators supported dabigatran doses of $110 \mathrm{mg}$ or $150 \mathrm{mg}$ twice daily for future large-scale studies [61].

\section{Prevention of thrombosis in elective} percutaneous coronary intervention (PCI)

A randomized, open-label phase II trial (ClinicalTrials.gov Identifier: NCT00818753) comparing dabigatran 110 and $150 \mathrm{mg}$ twice daily to unfractionated heparin, both in addition to standard dual antiplatelet regimen, in providing sufficient anticoagulation during cardiac catheterization was completed in September 2010. The efficacy of the anticoagulant effect of dabigatran was based on the number of patients who required rescue anticoagulant during the $\mathrm{PCl}$ as well as the number of patients who displayed signs of catheter-related thrombosis during the procedure. The incidence of major bleeding occurring up to 3 days after the $\mathrm{PCl}$ was also evaluated. Results from this study have not yet been published.

\section{Prevention of thrombus formation on mechanical heart valves}

Patients who receive an artificial heart valve require life long oral anticoagulation for the prevention of throm- boembolic events. As RE-LY showed dabigatran to be as effective, if not superior in preventing stroke in patients with $\mathrm{AF}$ and with less risk of major bleeding, investigation into whether dabigatran may serve as an alternative anticoagulant to heparin or LWMH in thromboprophylaxis and stroke prevention in patients with a mechanical heart valve has commenced. The efficacy of dabigatran compared with enoxaparin in the prevention of valve thrombus was studied in swine implanted with a mechanical aortic valve. Data revealed that dabigatran was as effective as enoxaparin for short-term thromboprophylaxis of mechanical valves as it best prevented valve thrombus and platelet deposition at 30 days without increased adverse events [62]. Another in vitro study compared thrombus formation on mechanical heart valve prostheses exposed to blood anticoagulated with dabigatran vs. unfractionated heparin or LMWH. The mean thrombus weight was comparable between each group and electron microscopy did not reveal any significant difference in thrombus formation [63]. Results from these early preclinical studies should encourage further investigation into the efficacy and safety of dabigatran for prevention of thrombus formation and stroke in patients with mechanical heart valves.

\section{Potential oral Ila inhibitors}

In addition to dabigatran etexilate, other novel direct thrombin inhibitors are currently being evaluated in phase I, II and III studies for the prevention of venous thromboembolism. The most investigated potential DTI is AZD0837 (AstraZeneca), a prodrug that is rapidly converted to its active form, $\mathrm{H} 067637$ via the intermediate H069927, and which has been reported to have superior pharmacologic properties compared with ximelegatran without its associated toxicities. It has an oral bioavailability of $22 \%-55 \%$ and a time to $C_{\max }$ of $0.7-1.5 \mathrm{~h}$ after oral administration. The half-life of $\mathrm{H} 067637$ is $9 \mathrm{~h}$ after a single dose. However the development of an extended release formulation allows once daily administration [64]. A multicentre, randomized, parallel, dose-guiding phase II study compared the efficacy and safety of 150 or $250 \mathrm{mg}$ twice daily doses of AZD0837 with warfarin (adjusted for goal INR 2-3) in the prevention of systemic embolism and stroke in patients with atrial fibrillation. AZD0837 at a dose of $150 \mathrm{mg}$ twice daily had a similar efficacy and tolerability profile to warfarin [64]. Gastrointestinal side effects were noted at increasing doses of AZD0837. AZD0837 has now entered a large phase III warfarin-controlled trial to determine its efficacy and safety for stroke prevention in atrial fibrillation.

\section{Conclusions}

In response to the limitations of heparins and vitamin $\mathrm{K}$ antagonists, research has focused on the development and 
utilization of direct thrombin inhibitors for the prevention and treatment of venous and selected arterial thromboembolism, heparin-induced thrombocytopenia, and acute coronary syndromes with and without $\mathrm{PCl}$. These newer anticoagulants offer several advantages over the traditional agents: direct inhibition of free and clot-bound thrombin, lack of required co-factors, a more predictable anticoagulant response, inhibition of thrombin-induced platelet aggregation and absence of immune-mediated thrombocytopenia. Currently, four parenteral DTIs are available in the United States, each licensed for a specific indication.

In the last decade there has been a strong drive to understand and investigate the use of oral direct thrombin inhibitors. Dabigatran etexilate is currently the most promising of the oral DTIs and offers various advantages, such as oral administration, predictable and reliable pharmacokinetic and pharmacodynamic profile, lack of interaction with cytochrome P450 enzymes or with other food and drugs, rapid onset of action, excellent safety profile, lack of need for routine monitoring, broad therapeutic window and fixed-dose administration, all qualities that make it an ideal anticoagulant. However, like all other anticoagulants, dabigatran etexilate carries a risk of bleeding. Currently, there is no established specific antidote to reverse its anticoagulant effect. Supportive strategies such as discontinuation of dabigatran etexilate, surgical haemostasis and transfusion of blood products are first line therapies to control severe bleeding. In the event of a potential overdose with dabigatran, early administration of activated charcoal or haemodialysis may be considered. Clotting agents such as recombinant activated factor VIla and prothrombin complex concentrates are also being investigated as potential therapies for the rapid reversal of dabigatran's anticoagulant effect in severe or lifethreatening bleeding [50].

Dabigatran etexilate has recently been FDA-approved and made available for stroke prevention in patients with atrial fibrillation, an action that will offer patients and clinicians the first new treatment option for this indication in more than 50 years. We look forward to seeing its impact on medical care and its potential to finally fulfill the unmet needs of anticoagulation therapy for the prevention and treatment of thromboembolic diseases.

\section{Competing Interests}

Dr Ansell has consulted for Boehringer Ingelheim, Ortho McNeil, Bristol Myers Squibb, and Daiichi.

\section{REFERENCES}

1 Tulinsky A. Molecular interactions of thrombin. Semin Thromb Hemost 1996; 22: 117-24.
2 Weitz JI, Leslie B, Hudoba M. Thrombin binds to soluble fibrin degradation products where it is protected from inhibition by heparin-antithrombin but susceptible to inactivation by antithrombin-independent inhibitors. Circulation 1998; 97: 544-52.

3 Weitz Jl, Hudoba M, Massel D, Maraganore J, Hirsh J. Clot-bound thrombin is protected from inhibition by heparin-antithrombin III but is susceptible to inactivation by antithrombin III-independent inhibitors. J Clin Invest 1990; 86: 385-91.

4 Bates SM, Weitz Jl. The mechanism of action of thrombin inhibitors. J Invasive Cardiol 2000; 12 (Suppl. F): 27F-32.

5 Stringer KA, Lindenfeld J. Hirudins: antithrombin anticoagulants. Ann Pharmacother 1992; 26: 1535-40.

6 Xiao Z, Theroux P. Platelet activation with unfractionated heparin at therapeutic concentrations and comparisons with a low-molecular-weight heparin and with a direct thrombin inhibitor. Circulation 1998; 97: 251-6.

7 Alban S. Pharmacological strategies for inhibition of thrombin activity. Curr Pharm Des 2008; 14: 1152-75.

8 Nutescu EA, Wittkowsky AK. Direct thrombin inhibitors for anticoagulation. Ann Pharmacother 2004; 38: 99-109.

9 Lee CJ, Badhwar G, Ansell JE. Oral Ila inhibitors. Hematol Oncol Clin North Am 2010; 24: 739-53, ix.

10 Weitz Jl, Hirsh J, Samama MM. New anticoagulant drugs: the seventh ACCP conference on antithrombotic and thrombolytic therapy. Chest 2004; 126 (3 Suppl.): 265S-86.

11 Rydel TJ, Ravichandran KG, Tulinsky A, Bode W, Huber R, Roitsch C, Fenton JW. The structure of a complex of recombinant hirudin and human alpha-thrombin. Science 1990; 249: 277-80.

12 Di Nisio M, Middeldorp S, Buller HR. Direct thrombin inhibitors. N Engl J Med 2005; 353: 1028-40.

13 Hirsh J, Bauer KA, Donati MB, Gould M, Samama MM, Weitz J. Parenteral anticoagulants: American College of Chest Physicians evidence-based clinical practice guidelines (8th Edition). Chest 2008; 133 (6 Suppl.): 141S-59S.

14 Nutescu EA, Shapiro NL, Chevalier A. New anticoagulant agents: direct thrombin inhibitors. Cardiol Clin 2008; 26: $169-87$, v-vi.

15 Greinacher A, Warkentin TE. The direct thrombin inhibitor hirudin. Thromb Haemost 2008; 99: 819-29.

16 Hirsh J, O’Donnell M, Weitz J. New anticoagulants. Blood 2005; 105: 453-63.

17 Iprivask [Package Insert]. Hunt Valley, MD: Canyon Pharmaceuticals, Inc, 2010.

18 Eriksson BI, Ekman S, Lindbratt S, Baur M, Bach D, Torholm C, Kalebo P, Close P. Prevention of thromboembolism with use of recombinant hirudin. Results of a double-blind, multicenter trial comparing the efficacy of desirudin (Revasc) with that of unfractionated heparin in patients having a total hip replacement. J Bone Joint Surg Am 1997; 79: 326-33. 
19 Eriksson $\mathrm{BI}$, Wille-Jorgensen $\mathrm{P}$, Kalebo $\mathrm{P}$, Mouret $\mathrm{P}$, Rosencher N, Bosch P, Baur M, Ekman S, Bach D, Lindbratt S, Close P. A comparison of recombinant hirudin with a low-molecular-weight heparin to prevent thromboembolic complications after total hip replacement. N Engl J Med 1997; 337: 1329-35.

20 Frame JN, Rice L, Bartholomew JR, Whelton A. Rationale and design of the PREVENT-HIT study: a randomized, open-label pilot study to compare desirudin and argatroban in patients with suspected heparin-induced thrombocytopenia with or without thrombosis. Clin Ther 2010; 32: 626-36.

21 Serruys PW, Herrman JP, Simon R, Rutsch W, Bode C, Laarman GJ, van Dijk R, van den Bos AA, Umans VA, Fox KA, Close $P$, and Deckers JW for the Helvetica Investigators. A comparison of hirudin with heparin in the prevention of restenosis after coronary angioplasty. Helvetica Investigators. N Engl J Med 1995; 333: 757-63.

22 The Global Use of Strategies to Open Occluded Coronary Arteries (GUSTO) Ilb Investigators. A comparison of recombinant hirudin with heparin for the treatment of acute coronary syndromes. N Engl J Med 1996; 335: 775-82.

23 Nafziger AN, Bertino JS Jr. Desirudin dosing and monitoring in moderate renal impairment. J Clin Pharmacol 2010; 50: 614-22.

24 Steinmetzer T, Sturzebecher J. [From fibrinogen and hirudin to synthetic anticoagulants. Rational design of thrombin inhibitors]. Pharm Unserer Zeit 2004; 33: 196-205.

25 Reed MD, Bell D. Clinical pharmacology of bivalirudin. Pharmacotherapy 2002; 22 (6 Pt 2): 105S-11S.

26 Robson R, White $\mathrm{H}$, Aylward P, Frampton C. Bivalirudin pharmacokinetics and pharmacodynamics: effect of renal function, dose, and gender. Clin Pharmacol Ther 2002; 71: 433-9.

27 Warkentin TE. Bivalent direct thrombin inhibitors: hirudin and bivalirudin. Best Pract Res Clin Haematol 2004; 17: 105-25.

28 Chew DP, Bhatt DL, Kimball W, Henry TD, Berger P, McCullough PA, Feit F, Bittl JA, Lincoff AM. Bivalirudin provides increasing benefit with decreasing renal function: a meta-analysis of randomized trials. Am J Cardiol 2003; 92: 919-23.

29 Steffel J, Luscher TF. Novel anticoagulants in clinical development: focus on factor $\mathrm{Xa}$ and direct thrombin inhibitors. J Cardiovasc Med (Hagerstown) 2009; 10: 616-23.

30 De Caterina R. The current role of anticoagulants in cardiovascular medicine. J Cardiovasc Med (Hagerstown) 2009; 10: 595-604.

31 Bittl JA, Chaitman BR, Feit F, Kimball W, Topol EJ. Bivalirudin versus heparin during coronary angioplasty for unstable or postinfarction angina: final report reanalysis of the Bivalirudin Angioplasty Study. Am Heart J 2001; 142: 952-9.

32 Angiomax [Package Insert]. Parsippany, NJ: The Medicines Company, 2005.

33 Lincoff AM, Bittl JA, Harrington RA, Feit F, Kleiman NS, Jackman JD, Sarembock IJ, Cohen DJ, Spriggs D, Ebrahimi R,
Keren G, Carr J, Cohen EA, Betriu A, Desmet W, Kereiakes DJ, Rutsch W, Wilcox RG, de Feyter PJ, Vahanian A, Topol EJ. Bivalirudin and provisional glycoprotein Ilb/Illa blockade compared with heparin and planned glycoprotein Ilb/Illa blockade during percutaneous coronary intervention: REPLACE-2 randomized trial. JAMA 2003; 289: 853-63.

34 White $\mathrm{H}$. Thrombin-specific anticoagulation with bivalirudin versus heparin in patients receiving fibrinolytic therapy for acute myocardial infarction: the HERO-2 randomised trial. Lancet 2001; 358: 1855-63.

35 Mahaffey KW, Lewis BE, Wildermann NM, Berkowitz SD, Oliverio RM, Turco MA, Shalev Y, Ver Lee P, Traverse JH, Rodriguez AR, Ohman EM, Harrington RA, Califf RM. The anticoagulant therapy with bivalirudin to assist in the performance of percutaneous coronary intervention in patients with heparin-induced thrombocytopenia (ATBAT) study: main results. J Invasive Cardiol 2003; 15:611-6.

36 Koster A, Dyke CM, Aldea G, Smedira NG, McCarthy HL 2nd, Aronson S, Hetzer R, Avery E, Spiess B, Lincoff AM. Bivalirudin during cardiopulmonary bypass in patients with previous or acute heparin-induced thrombocytopenia and heparin antibodies: results of the CHOOSE-ON trial. Ann Thorac Surg 2007; 83: 572-7.

37 Clayton SB, Acsell JR, Crumbley AJ 3rd, Uber WE. Cardiopulmonary bypass with bivalirudin in type II heparin-induced thrombocytopenia. Ann Thorac Surg 2004; 78: 2167-9.

38 Keisu M, Andersson TB. Drug-induced liver injury in humans: the case of ximelagatran. Handb Exp Pharmacol 2010; 196: 407-18.

39 Blech S, Ebner T, Ludwig-Schwellinger E, Stangier J, Roth W. The metabolism and disposition of the oral direct thrombin inhibitor, dabigatran, in humans. Drug Metab Dispos 2008; 36: 386-99.

40 Stangier J, Rathgen K, Stahle H, Gansser D, Roth W. The pharmacokinetics, pharmacodynamics and tolerability of dabigatran etexilate, a new oral direct thrombin inhibitor, in healthy male subjects. Br J Clin Pharmacol 2007; 64: 292-303.

41 Stangier J. Clinical pharmacokinetics and pharmacodynamics of the oral direct thrombin inhibitor dabigatran etexilate. Clin Pharmacokinet 2008; 47: 285-95.

42 Eriksson BI, Quinlan DJ, Weitz Jl. Comparative pharmacodynamics and pharmacokinetics of oral direct thrombin and factor Xa inhibitors in development. Clin Pharmacokinet 2009; 48: 1-22.

43 Stangier J, Stahle H, Rathgen K, Roth W, Shakeri-Nejad K. Pharmacokinetics and pharmacodynamics of dabigatran etexilate, an oral direct thrombin inhibitor, are not affected by moderate hepatic impairment. J Clin Pharmacol 2008; 48 : 1411-9.

44 Stangier J, Eriksson Bl, Dahl OE, Ahnfelt L, Nehmiz G, Stahle H, Rathgen K, Svard R. Pharmacokinetic profile of the oral direct thrombin inhibitor dabigatran etexilate in healthy volunteers and patients undergoing total hip replacement. J Clin Pharmacol 2005; 45: 555-63. 
45 Stangier J, Stahle H, Rathgen K, Fuhr R. Pharmacokinetics and pharmacodynamics of the direct oral thrombin inhibitor dabigatran in healthy elderly subjects. Clin Pharmacokinet 2008; 47: 47-59.

46 Stangier J, Clemens A. Pharmacology, pharmacokinetics, and pharmacodynamics of dabigatran etexilate, an oral direct thrombin inhibitor. Clin Appl Thromb Hemost 2009; 15 (Suppl. 1): 9S-16S.

47 Stangier J, Rathgen K, Stahle H, Reseski K, Kornicke T, Roth W. Coadministration of dabigatran etexilate and atorvastatin: assessment of potential impact on pharmacokinetics and pharmacodynamics. Am J Cardiovasc Drugs 2009; 9: 59-68.

48 Walenga JM, Adiguzel C. Drug and dietary interactions of the new and emerging oral anticoagulants. Int J Clin Pract 2010; 64: 956-67.

49 Wittkowsky AK. New oral anticoagulants: a practical guide for clinicians. J Thromb Thrombolysis 2010; 29: 182-91.

50 van Ryn J, Stangier J, Haertter S, Liesenfeld KH, Wienen W, Feuring $M$, Clemens A. Dabigatran etexilate - a novel, reversible, oral direct thrombin inhibitor: interpretation of coagulation assays and reversal of anticoagulant activity. Thromb Haemost 2010; 103: 1116-27.

51 Eriksson BI, Dahl OE, Ahnfelt L, Kalebo P, Stangier J, Nehmiz G, Hermansson K, Kohlbrenner V. Dose escalating safety study of a new oral direct thrombin inhibitor, dabigatran etexilate, in patients undergoing total hip replacement: BISTRO I. J Thromb Haemost 2004; 2: 1573-80.

52 Eriksson BI, Dahl OE, Buller HR, Hettiarachchi R, Rosencher N, Bravo ML, Ahnfelt L, Piovella F, Stangier J, Kalebo P, Reilly P. A new oral direct thrombin inhibitor, dabigatran etexilate, compared with enoxaparin for prevention of thromboembolic events following total hip or knee replacement: the BISTRO II randomized trial. J Thromb Haemost 2005; 3: 103-11.

53 Wolowacz SE, Roskell NS, Plumb JM, Caprini JA, Eriksson BI. Efficacy and safety of dabigatran etexilate for the prevention of venous thromboembolism following total hip or knee arthroplasty. A meta-analysis. Thromb Haemost 2009; 101: 77-85.

54 Eriksson BI, Dahl OE, Rosencher N, Kurth AA, van Dijk CN, Frostick SP, Kalebo P, Christiansen AV, Hantel S, Hettiarachchi R, Schnee J, Buller HR. Oral dabigatran etexilate vs. subcutaneous enoxaparin for the prevention of venous thromboembolism after total knee replacement: the RE-MODEL randomized trial. J Thromb Haemost 2007; 5: 2178-85.

55 Eriksson BI, Dahl OE, Rosencher N, Kurth AA, van Dijk CN, Frostick SP, Prins MH, Hettiarachchi R, Hantel S, Schnee J,
Buller HR. Dabigatran etexilate versus enoxaparin for prevention of venous thromboembolism after total hip replacement: a randomised, double-blind, non-inferiority trial. Lancet 2007; 370: 949-56.

56 Ginsberg JS, Davidson BL, Comp PC, Francis CW, Friedman RJ, Huo MH, Lieberman JR, Muntz JE, Raskob GE, Clements ML, Hantel S, Schnee JM, Caprini JA. Oral thrombin inhibitor dabigatran etexilate vs North American enoxaparin regimen for prevention of venous thromboembolism after knee arthroplasty surgery. J Arthroplasty 2009; 24: 1-9.

57 Huo M, Eriksson B, Dahl O, Kurth A, Hantel S, Hermansson K, Schnee J, Friedman R. Oral dabigatran versus enoxaparin for thromboprophylaxis after primary total hip arthroplasty: the RE-NOVATE II randomized trial. In: 15th Congress of the European Hematology Association (EHA) (Abstract \#0564). Barcelona, Spain; 2010.

58 Schulman S, Kearon C, Kakkar AK, Mismetti P, Schellong S, Eriksson H, Baanstra D, Schnee J, Goldhaber SZ. Dabigatran versus warfarin in the treatment of acute venous thromboembolism. N Engl J Med 2009; 361: 2342-52.

59 Ezekowitz MD, Reilly PA, Nehmiz G, Simmers TA, Nagarakanti R, Parcham-Azad K, Pedersen KE, Lionetti DA, Stangier J, Wallentin L. Dabigatran with or without concomitant aspirin compared with warfarin alone in patients with nonvalvular atrial fibrillation (PETRO Study). Am J Cardiol 2007; 100: 1419-26.

60 Connolly SJ, Ezekowitz MD, Yusuf S, Reilly PA, Wallentin L. Newly identified events in the RE-LY trial. N Engl J Med 2010; 363: 1875-6.

61 Oldgren J. RE-DEEM: Dabigatran added to dual antiplatelet therapy resulted in acceptable bleeding rates post-MI. In: American Heart Association Scientific Sessions (abstract \#165). Orlando, FL; 2009.

62 McKellar S, Abel S, Camp C, Ereth M, Schaff H. Dabigatran is effective for thromboprophylaxis of mechanical heart valves. In: American Association for Thoracic Surgery 90th Annual Meeting (abstract). Toronto, ON, Canada; 2010.

63 Maegdefessel L, Linde T, Krapiec F, Hamilton K, Steinseifer U, van Ryn J, Raaz U, Buerke M, Werdan K, Schlitt A. In vitro comparison of dabigatran, unfractionated heparin, and low-molecular-weight heparin in preventing thrombus formation on mechanical heart valves. Thromb Res 2010; 126: e196-200.

64 Olsson SB, Rasmussen LH, Tveit A, Jensen E, Wessman P, Panfilov S, Wahlander K. Safety and tolerability of an immediate-release formulation of the oral direct thrombin inhibitor AZD0837 in the prevention of stroke and systemic embolism in patients with atrial fibrillation. Thromb Haemost 2010; 103: 604-12. 